\title{
Rescue Treatment of Thromboembolic Complications during Endovascular Treatment of Cerebral Aneurysms: A Meta-Analysis
}

\author{
W. Brinjikji, S.F. Morales-Valero, M.H. Murad, H.J. Cloft, and D.F. Kallmes
}

\begin{abstract}
BACKGROUND AND PURPOSE: Intraprocedural thrombus formation during endovascular treatment of intracranial aneurysms is often treated with glycoprotein IIb/IIla inhibitors and, in some instances, fibrinolytic therapy. We performed a meta-analysis evaluating the safety and efficacy of GP Ilb/IIla inhibitors compared with fibrinolysis. We also evaluated the safety and efficacy of abciximab, an irreversible inhibitor, compared with tirofiban and eptifibatide, reversible inhibitors of platelet function.
\end{abstract}

MATERIALS AND METHODS: We performed a comprehensive literature search for studies on rescue therapy for intraprocedural thromboembolic complications with glycoprotein Ilb/Illa inhibitors or fibrinolysis during endovascular treatment of intracranial aneurysms. We studied rates of periprocedural stroke/hemorrhage, procedure-related morbidity and mortality, immediate arterial recanalization, and long-term good clinical outcome. Event rates were pooled across studies by using random-effects meta-analysis.

RESULTS: Twenty-three studies with 516 patients were included. Patients receiving GP IIb/IIla inhibitors had significantly lower perioperative morbidity from stroke/hemorrhage compared with those treated with fibrinolytics $111.0 \% ; 95 \% \mathrm{Cl}, 7.0 \%-16.0 \%$ versus $29.0 \% ; 95 \% \mathrm{Cl}, 13.0 \%-55.0 \% ; P=.04)$ and were significantly less likely to have long-term morbidity $(16.0 \% ; 95 \% \mathrm{Cl}, 11.0 \%-21.0 \%$ versus $35.0 \% ; 95 \% \mathrm{Cl}, 17.0 \%-58.0 \% ; P=.04)$. There was a trend toward higher recanalization rates among patients treated with glycoprotein Ilb/IIla inhibitors compared with those treated with fibrinolytics $(72.0 \% ; 95 \% \mathrm{Cl}, 64.0 \%-78.0 \%$ versus $50.0 \%$; $95 \% \mathrm{Cl}, 28.0 \%-73.0 \%$; $P=.08)$. Patients receiving tirofiban or eptifibatide had significantly higher recanalization rates compared with those treated with abciximab (83.0\%; 95\% Cl, 68.0\%-91.0\% versus 66.0\%; 95\% Cl, 58.0\%-74.0\%; $P=.05$ ). No difference in recanalization was seen in patients receiving intra-arterial $(77.0 \%$; $95 \% \mathrm{Cl}, 66.0 \%-85.0 \%)$ or intravenous GP Ilb/Illa inhibitors $(70.0 \%$; $95 \% \mathrm{Cl}, 57.0 \%-80.0 \%$, $P=.36)$.

CONCLUSIONS: Rescue therapy with thrombolytic agents resulted in significantly more morbidity than rescue therapy with glycoprotein Ilb/Illa inhibitors. Tirofiban/eptifibatide resulted in significantly higher recanalization rates compared with abciximab.

ABBREVIATIONS: GP IIb/IIla = glycoprotein Ilb/Illa; IA = intra-arterial; TIMI = Thrombolysis in Myocardial Infarction

$\mathbf{P}$ eriprocedural thromboembolic complications from endovascular treatment of intracranial aneurysms occur in $2 \%-15 \%$ of patients. ${ }^{1}$ Intraprocedural thrombus formation is often treated with pharmacologic rescue, by using intra-arterial or intravenous administration of glycoprotein IIb/IIIa (GP IIb/IIIa) inhibitors or fibrinolytics. The primary goal of rescue therapy is to recanalize

Received April 17, 2014; accepted after revision June 23.

From the Departments of Radiology (W.B., H.J.C., D.F.K.) and Neurosurgery (S.F.M.-V., H.J.C., D.F.K.) and Center for Science of Healthcare Delivery (M.H.M.), Mayo Clinic, Rochester, Minnesota.

Please address correspondence to Waleed Brinjikji, MD, Department of Radiology, Mayo Clinic, 200 SW First St, Rochester, MN 55905; e-mail: brinjikji.waleed@ mayo.edu

三 Indicates article with supplemental on-line table.

http://dx.doi.org/10.3174/ajnr.A4066 the artery to avoid permanent neurologic deficits. Many studies have described intraprocedural administration of GP IIb/IIIa inhibitors and thrombolytic agents during endovascular treatment of intracranial aneurysms. Some studies have suggested that patients receiving GP IIb/IIIa inhibitors have better outcomes than those treated with fibrinolytic therapy. Studies have also examined the comparative efficacy of irreversible GP IIb/IIIa inhibitor agents (abciximab) and reversible agents (tirofiban/eptifibatide) and the comparative efficacy of intra-arterial and intravenous administration of GP IIb/IIIa inhibitors, but they have not demonstrated any significant differences in recanalization rates and outcomes. ${ }^{2,3}$ Overall however, the evidence is limited to small case series. We performed a meta-analysis of the literature examining angiographic and clinical outcomes in patients treated with GP IIb/IIIa inhibitors and fibrinolytic therapy for intraprocedural 
Table 1: Rescue therapy outcomes with GP IIb/IIla inhibitors versus fibrinolytics

\begin{tabular}{|c|c|c|c|c|c|}
\hline Outcome & GP IIb/IIla Inhibitor \% (95\% Cl) & $I^{2}$ & Fibrinolytic \% (95\% Cl) & $1^{2}$ & $P$ Value \\
\hline Postoperative clinical stroke & $14.0(8.0-23.0)$ & 65 & $27.0(11.0-51.0)$ & 53 & .20 \\
\hline Postoperative infarct on imaging & $28.0(19.0-39.0)$ & 56 & $39.0(19.0-63.0)$ & 0 & .42 \\
\hline Postoperative hemorrhage & $7.0(4.0-10.0)$ & 0 & $14.0(6.0-31.0)$ & 26 & .12 \\
\hline Perioperative morbidity from stroke/hemorrhage & $11.0(7.0-16.0)$ & 10 & $29.0(13.0-55.0)$ & 55 & .04 \\
\hline Perioperative mortality from stroke/hemorrhage & $6.0(4.0-9.0)$ & 0 & $12.0(5.0-25.0)$ & 0 & .16 \\
\hline Long-term good neurologic outcome & $82.0(78.0-86.0)$ & 0 & $65.0(42.0-83.0)$ & 43 & .07 \\
\hline Long-term morbidity & $16.0(11.0-21.0)$ & 13 & $35.0(17.0-58.0)$ & 43 & .04 \\
\hline Recanalization rate & $72.0(64.0-78.0)$ & 49 & $50.0(28.0-73.0)$ & 37 & .08 \\
\hline
\end{tabular}

thrombus formation during intracranial aneurysm treatment. ${ }^{4}$ We also performed subgroup analyses to compare outcomes of patients treated with abciximab versus tirofiban/eptifibatide and those treated with intra-arterial (IA) and intravenous GP IIb/IIIa rescue therapy.

\section{MATERIALS AND METHODS}

A comprehensive literature search of the data bases PubMed, Ovid MEDLINE, and Ovid EMBASE was designed and conducted by an experienced librarian with input from the authors. The key words "intracranial aneurysm," "endovascular therapy," "fibrinolytic," "tPA," "glycoprotein IIb/IIIa," "abciximab," “coil," "thromboembolic," and "rescue" were used in both "AND" and "OR" combinations. The search was limited to articles published from 1990 to January 2014 in the English language only. All studies reporting patients treated with GP IIb/IIIa inhibitors or fibrinolysis during endovascular treatment of intracranial aneurysms were selected. The inclusion criteria were the following: a series of $>5$ patients, with available data on periprocedural complications and angiographic outcomes. Studies performed by using administrative/insurance data bases were excluded. Two reviewers independently selected the included studies. For each study, we independently extracted the following information: recanalization rate, perioperative clinical stroke, perioperative infarct on imaging, perioperative hemorrhage, perioperative morbidity and mortality from stroke/hemorrhage, long-term good neurologic outcome, and long-term morbidity. Perioperative complications were identified as those that occurred within 30 days of the procedure. The recanalization rate was defined as a Thrombolysis in Cerebral Infarction score of $\geq 2$ or a Thrombolysis in Myocardial Infarction (TIMI) score of $\geq 2$. In cases in which patients underwent rescue therapy for a TIMI/TICI score of 2 , recanalization was defined as a 1-point improvement in the recanalization rate. In series in which TIMI/TICI scores were not provided, recanalization was defined by using the words "near-complete or complete recanalization." Patients included in the long-term outcome analysis required a minimum of 3 months of follow-up. Good clinical outcome was defined as an mRS score of $\leq 2$.

The primary objective of this study was to compare outcomes among patients treated with GP IIb/IIIa inhibitors and those treated with fibrinolytics. For this comparison, we did not control for the method of administration (IV or IA) or the drug used (ie, abciximab, tirofiban, eptifibatide, recombinant tissue plasminogen activator, streptokinase, and so forth). We performed 2 subgroup analyses: 1) comparing outcomes of patients treated with large-molecule/irreversible GP IIb/IIIa inhibitors (abciximab) with those treated with small-molecule/reversible GP IIb/IIIa in- hibitors (tirofiban/eptifibatide), and 2) comparing outcomes of patients receiving IA GP IIb/IIIa inhibitors versus IV GP IIb/IIIa inhibitors.

\section{Statistical Analysis}

Most of the included studies were noncomparative. Therefore, we estimated from each cohort the cumulative incidence (event rate) and $95 \%$ confidence interval for each outcome. Event rates for each intervention were pooled in a meta-analysis across studies by using the random-effects model. ${ }^{5}$ In this model, studies are weighted by the inverse of their variance (ie, larger studies will have larger weight). The incidence rates of the different outcomes were compared between GP IIb/IIIa cohorts and fibrinolytic treatment cohorts by using an interaction test as described by Altman and Bland. ${ }^{6}$ Additional comparisons were made between abciximab and tirofiban/eptifibatide and between IA versus IV GP IIb/IIIa inhibitors. Heterogeneity of the treatment effect across studies was evaluated by using the $\mathrm{I}^{2}$ statistic. $^{7}$

\section{RESULTS}

\section{Literature Review}

Studies included in our literature review are summarized in the On-line Table. Our literature search yielded 623 articles; 562 articles were excluded after reading the abstract alone. Twenty-one studies were excluded for not meeting our minimum size criterion of $\geq 5$ patients. Seventeen studies were excluded because they reported rescue therapy during endovascular procedures other than aneurysm treatment. Twenty-three studies met our inclusion criteria. In total, 533 patients were included in this study. Four hundred eighty patients received GP IIb/IIIa inhibitors (90.0\%), and 63 patients (11.8\%) received fibrinolytic therapy. Eighteen studies provided the proportion of patients during the study time period receiving rescue therapy for thromboembolic complications. From these studies, 444/7276 (6.1\%) received rescue therapy. Among patients receiving Gp IIb/IIIa inhibitors, 322 patients received abciximab and 145 patients received either tirofiban or eptifibatide. One hundred forty-nine patients received IV GP IIb/IIIa inhibitors, and 284 patients received IA GP IIb/IIIa inhibitors.

\section{GP IIb/IIla versus Fibrinolytics}

Outcomes for GP IIb/IIIa inhibitors versus fibrinolytic therapy for rescue treatment are summarized in Table 1. The postoperative clinical stroke rate was $14.0 \%$ (95\% CI, 8.0-23.0) for patients treated with GP IIb/IIIa inhibitor compared with $27.0 \%$ (95\% CI, 11.0-51.0) for those treated with fibrinolytics $(P=.20)$. The postoperative hemorrhage rate was $7.0 \%(95 \%$ 
Table 2: Rescue therapy outcomes with GP Ilb/IIla inhibitors: abciximab versus tirofiban/eptifibatide

\begin{tabular}{|c|c|c|c|c|c|}
\hline Outcome & Abciximab \% (95\% Cl) & $1^{2}$ & Tirofiban/Eptifibatide \% (95\% Cl) & $\mathbf{I}^{2}$ & $P$ Value \\
\hline Postoperative clinical stroke & $14.0(8.0-25.0)$ & 50 & $13.0(4.0-33.0)$ & 77 & .86 \\
\hline Postoperative infarct on imaging & $28.0(19.0-39.0)$ & 44 & $37.0(9.0-76.0)$ & 81 & .67 \\
\hline Postoperative hemorrhage & $7.0(4.0-10.0)$ & 0 & $14.0(6.0-31.0)$ & 26 & .12 \\
\hline Perioperative morbidity from stroke/hemorrhage & $12.0(8.0-18.0)$ & 4 & $8.0(4.0-16.0)$ & 3 & .30 \\
\hline Perioperative mortality from stroke/hemorrhage & $6.0(4.0-10.0)$ & 0 & $6.0(3.0-12.0)$ & 0 & .16 \\
\hline Long-term good neurologic outcome & $85.0(79.0-89.0)$ & 0 & $78.0(69.0-85.0)$ & 0 & .15 \\
\hline Long-term morbidity & $14.0(9.0-21.0)$ & 15 & $18.0(11.0-29.0)$ & 19 & .37 \\
\hline Recanalization rate & $66.0(58.0-74.0)$ & 32 & $83.0(68.0-91.0)$ & 60 & .05 \\
\hline
\end{tabular}

Table 3: Rescue therapy outcomes with GP IIb/IIIa inhibitors: IA versus IV administration

\begin{tabular}{|c|c|c|c|c|c|}
\hline Outcome & IA GP IIb/IIla \% (95\% CI) & $\mathrm{I}^{2}$ & IV GP IIb/IIla \% (95\% CI) & $1^{2}$ & $P$ Value \\
\hline Postoperative clinical stroke & $14.0(7.0-26.0)$ & 70 & $14.0(8.0-26.0)$ & 0 & .94 \\
\hline Postoperative infarct on imaging & $33.0(20.0-50.0)$ & 58 & $23.0(13.0-36.0)$ & 28 & .30 \\
\hline Postoperative hemorrhage & $5.0(3.0-9.0)$ & 0 & $7.0(3.0-15.0)$ & 18 & .66 \\
\hline Perioperative morbidity from stroke/hemorrhage & $10.0(7.0-15.0)$ & 0 & $13.0(6.0-27.0)$ & 34 & .57 \\
\hline Perioperative mortality from stroke/hemorrhage & $6.0(4.0-10.0)$ & 0 & $8.0(4.0-14.0)$ & 0 & .53 \\
\hline Long-term good neurologic outcome & $83.0(76.0-88.0)$ & 0 & $78.0(69.0-85.0)$ & 10 & .37 \\
\hline Long-term morbidity & $14.0(10.0-21.0)$ & 0 & $17.0(11.0-25.0)$ & 2 & .56 \\
\hline Recanalization rate & $77.0(66.0-85.0)$ & 58 & $70.0(57.0-80.0)$ & 33 & .36 \\
\hline
\end{tabular}

CI, 4.0-10.0) for patients treated with GP IIb/IIIa inhibitors compared with $14.0 \%$ (95\% CI, 6.0-31.0) for those treated with thrombolytics $(P=.12)$. Perioperative morbidity from stroke/hemorrhage was significantly higher in the fibrinolytics group (29.0\%; 95\% CI, 13.0-55.0) compared with the GP IIb/ IIIa group (11.0\%; 95\% CI, 7.0-16.0; $P=.04)$. Long-term morbidity was significantly higher in the fibrinolytics group (35.0\%; 95\% CI, 17.0-158.0) compared with the GP IIb/IIIa group $(16.0 \%$; 95\% CI, $11.0-21.0 ; P=.04)$. There was a trend toward significantly higher recanalization rates with GP IIb/ IIIa inhibitors $(72.0 \%$; 95\% CI, 64.0-78.0) compared with fibrinolytics $(50.0 \%$; 95\% CI, 28.0-73.0; $P=.08)$.

\section{Abciximab versus Tirofiban/Eptifibatide}

Comparison of outcomes of patients receiving abciximab and tirofiban/eptifibatide are summarized in Table 2. Patients receiving tirofiban/eptifibatide had significantly higher recanalization rates (83.0\%; 95\% CI, 68.0-91.0) compared with those receiving abciximab (66.0\%; 95\% CI, 58.0-74.0; $P=.05)$. Patients treated with tirofiban/eptifibatide had a non-statistically significant higher rate of postoperative hemorrhage (14.0\%; 95\% CI, $6.0-$ $31.0)$ compared with those treated with abciximab $(7.0 \%$; $95 \% \mathrm{CI}$, $4.0-10.0 ; P=.12)$. No difference was seen in perioperative morbidity and mortality or long-term morbidity.

\section{Intra-Arterial versus Intravenous GP IIb/IIla Inhibitors}

Comparison of outcomes of IA versus IV GP IIb/IIIa inhibitors is summarized in Table 3. No difference in the recanalization rate was seen on the basis of the method of administration of GP IIb/IIIa inhibitors because patients treated with IA therapy had a recanalization rate of $77.0 \%(95 \% \mathrm{CI}, 66.0-85.0)$ and those treated with IV therapy had a recanalization rate of $70.0 \%$ (95\% CI, 57.0-80.0; $P=.36$ ). Clinical outcomes and complication rates did not differ by method of GP IIb/IIIa inhibitor administration.

\section{DISCUSSION}

Our systematic review of rescue therapy for the treatment of intraoperative thromboembolic complications in the setting of aneurysm coiling demonstrated higher rates of short- and long-term morbidity among patients treated with fibrinolysis relative to those receiving GP IIb/IIIa inhibitors. In addition, we found a trend toward improved recanalization rates with GP IIb/IIIa inhibitors compared with thrombolytics. Patients receiving tirofiban/eptifibatide had significantly higher recanalization rates compared with those receiving abciximab; however, no difference was seen in clinical outcomes. No difference in outcome was seen among patients receiving intra-arterial and intravenous rescue therapy with GP IIb/IIIa inhibitors. These data should prompt practitioners to avoid fibrinolytics in place of GP IIb/IIIa agents for rescue therapy during coil embolization.

In most case series, the rate of rescue therapy for thromboembolic complications ranged between $5 \%$ and $10 \% .^{1,3,8-19}$ Our systematic review found that approximately $6 \%$ of patients received rescue therapy during the treatment of intracranial aneurysms. Clinical outcomes of patients receiving GP IIb/IIIa inhibitors and fibrinolytics are variable. In a study of 592 patients undergoing rescue therapy in a large administrative data base, Brinjikji et $\mathrm{al}^{4}$ found that patients with unruptured aneurysms receiving fibrinolytics had significantly higher rates of discharge to institutions other than home $(37.5 \%$ versus $7.4 \%)$. Patients with ruptured aneurysms receiving fibrinolytics had significantly higher rates of in-hospital mortality (26.0\% versus $14.5 \%$ ) and discharge to institutions other than home (59.4\% versus $36.5 \%)$. Our study found significantly higher rates of short- and long-term morbidity among patients receiving fibrinolytic therapy for rescue treatment. Furthermore, there was a trend toward improved recanalization rates among patients treated with GP IIb/IIIa inhibitors.

The infarction rate among patients receiving rescue therapy ranges between $10 \%$ and $40 \%$, with higher rates generally seen in studies with postoperative MR imaging. ${ }^{1,3,8-19}$ In a series of 477 patients with 515 intracranial aneurysms, Ries et $\mathrm{al}^{1}$ reported that 
48 patients (10\%) had thromboembolic events, 42 of these patients received rescue therapy with GP IIb/IIIa inhibitors, and 1 patient received rescue therapy with $\mathrm{rPA}$. Of the patients who did not receive rescue therapy, $3 / 5$ had infarcts, while $31 \%$ of patients receiving GP IIb/IIIa inhibitor rescue therapy had infarctions on CT. Linfante et $\mathrm{al}^{15}$ found that approximately $10 \%$ of patients undergoing endovascular embolization of intracranial aneurysms required intra-arterial GP IIb/IIIa inhibitor rescue therapy, with an infarct and hemorrhage rate of $0 \%$. Many prior studies that have demonstrated high infarct rates on postoperative imaging also show that many of these infarcts are clinically silent. ${ }^{1,8,14}$ In our study, there was no significant difference in the rate of clinical stroke and infarction on imaging between patients treated with GP IIb/IIIa inhibitor and those receiving thrombolytics.

The efficacy of small-molecule/reversible GP IIb/IIIa inhibitors (tirofiban/eptifibatide) relative to the large-molecule/irreversible inhibitor (abciximab) has not been well-established. One might assume that reversible, competitive inhibitory agents such as tirofiban/eptifibatide may lose potency, thus leading to decreased recanalization rates. In a meta-analysis of abciximab versus small-molecule GP IIb/IIIa inhibitors among patients receiving percutaneous coronary interventions, Gurm et $\mathrm{al}^{20}$ found no difference in clinical and angiographic outcomes between these 2 agents. In a large randomized controlled trial of abciximab versus eptifibatide for coronary revascularization, Zeymer et $\mathrm{al}^{21}$ found similar safety and efficacy rates between the 2 drugs. We found significantly higher recanalization rates, with no difference in clinical outcome, when comparing small-molecule GP IIb/IIIa inhibitors and abciximab.

The efficacy of intravenous-versus-intra-arterial administration of GP IIb/IIIa inhibitors for rescue therapy is also not wellestablished. One might assume that local intra-arterial administration of GP IIb/IIIa inhibitors at the site of thrombus formation would yield higher recanalization rates and thus improved clinical outcomes due to increased local concentrations of the therapeutic agent. A number of studies in the cardiology literature, in which GP IIb/IIIa inhibitors are routinely used in percutaneous coronary intervention, have examined the safety and efficacy of both the route and type of GP IIb/IIIa inhibitor administration. In a meta-analysis of randomized controlled trials of intracoronary versus intravenous administration of glycoprotein IIb/IIIa inhibitors during percutaneous coronary intervention for acute coronary syndrome, Friedland et $\mathrm{al}^{22}$ found that intracoronary administration resulted in higher recanalization rates and short-term mortality after intervention. Fu et $\mathrm{al}^{23}$ found that intracoronary administration increased coronary flow and myocardial reperfusion but did not improve outcomes compared with intravenous administration. While intra-arterial administration of GP IIb/IIIa inhibitors may lead to higher concentrations of the agent at the site of the thrombus, an intravenous bolus of GP IIb/IIIa inhibitors has been found to reduce platelet aggregation to $<20 \%$ within 10 minutes of administration. ${ }^{24}$ It may be that intra-arterial administration is beneficial only in the short term, which may not be sufficient to provide clinical benefit. Our study found no differences in recanalization or clinical outcomes between patients receiving IA or IV GP IIb/IIIa inhibitors.

\section{Limitations}

Our study has limitations. The data on which this meta-analysis is based are affected by publication bias. Studies with favorable results are more likely to be published. Moreover, the limitations of single-center experiences for selection bias and potential complication under-reporting are well-known. Many details were lacking from the studies included in our analysis. For example, many studies did not provide TICI/TIMI grading for vessel recanalization. We did not stratify outcomes on the basis of aneurysm rupture status. Reporting of long-term neurologic outcomes was inconsistent across studies. In addition, many of the series analyzed and included in our analysis were cases collected during several years, and it is possible that complication rates have improved as a result of increased operator experience and skill and improved devices and technology. Regarding the method of GP IIb/IIIa administration, there was variation in how intravenous doses were administered (loading dose alone, loading dose plus drip, or drip alone). The comparisons reported in this meta-analysis are made across studies, not within studies; this difference greatly weakens inference. Most of the studies in our analysis were noncomparative, and groups were not randomized. An ideal meta-analysis comparing variable pharmacologic therapies would include only comparative studies with randomized groups. Overall, the quality of the studies included in this analysis was low. If one used the Grading of Recommendations, Assessment, Development, and Evaluation framework, the quality of evidence (confidence in estimates) is very low because of imprecision, heterogeneity, and methodologic limitations of the included studies. ${ }^{25-27}$

\section{CONCLUSIONS}

In this study, rescue therapy with GP IIb/IIIa inhibitors is associated with less long- and short-term morbidity compared with fibrinolytics for rescue therapy during intracranial aneurysm coiling. Our meta-analysis suggests that eptifibatide/tirofiban treatment results in significantly higher recanalization rates than treatment with abciximab. No difference in outcome was seen on the basis of the method of administration of GP IIb/IIIa inhibitors. Further clinical trials might study the relative safety and efficacy of various GP IIb/IIIa inhibitors and methods of administration to help determine the best treatment for intraprocedural thromboembolic complications during intracranial aneurysm treatment.

Disclosures: Harry J. Cloft_UNRELATED: Grants/Grants Pending: Cordis Endovascular, ${ }^{*}$ Comments: site Principal Investigator at enrolling site for Stenting and Angioplasty with Protection in Patients and HIgh Risk for Endarterectomy registry sponsored by Cordis Endovascular. David Kallmes-UNRELATED: Consultancy: GE Healthcare, ${ }^{*}$ ev3,* Comments: planning and implementation of clinical trials; Grants/Grants Pending: MicroVention, ${ }^{*}$ ev3,, Codman, ${ }^{*}$ Sequent,* SurModics,* Benvenue Medical, ${ }^{*}$ Comments: planning and implementation of clinical trials, preclinical research; Royalties: University of Virginia Patent Foundation, Comments: Spine Fusion. *Money paid to the institution.

\section{REFERENCES}

1. Ries T, Siemonsen S, Grzyska U, et al. Abciximab is a safe rescue therapy in thromboembolic events complicating cerebral aneurysm coil embolization: single center experience in 42 cases and review of the literature. Stroke 2009;40:1750-57

2. Jeong HW, Jin SC. Intra-arterial infusion of a glycoprotein IIb/IIIa antagonist for the treatment of thromboembolism during coil em- 
bolization of intracranial aneurysm: a comparison of abciximab and tirofiban. AJNR Am J Neuroradiol 2013;34:1621-25

3. Jones RG, Davagnanam I, Colley S, et al. Abciximab for treatment of thromboembolic complications during endovascular coiling of intracranial aneurysms. AJNR Am J Neuroradiol 2008;29:1925-29

4. Brinjikji W, McDonald JS, Kallmes DF, et al. Rescue treatment of thromboembolic complications during endovascular treatment of cerebral aneurysms. Stroke 2013;44:1343-47

5. DerSimonian R, Laird N. Meta-analysis in clinical trials. Control Clin Trials 1986;7:177-88

6. Altman DG, Bland JM. Interaction revisited: the difference between two estimates. $B M J$ 2003;326:219

7. Higgins JP, Thompson SG, Deeks JJ, et al. Measuring inconsistency in meta-analyses. $B M J$ 2003;327:557-60

8. Aggour M, Pierot L, Kadziolka K, et al. Abciximab treatment modalities for thromboembolic events related to aneurysm coiling. $\mathrm{Neu}$ rosurgery 2010;67:503-08

9. Aviv RI, O'Neill R, Patel MC, et al. Abciximab in patients with ruptured intracranial aneurysms. AJNR Am J Neuroradiol 2005;26: $1744-50$

10. Brooks NP, Turk AS, Niemann DB, et al. Frequency of thromboembolic events associated with endovascular aneurysm treatment: retrospective case series. J Neurosurg 2008;108:1095-100

11. Bruening R, Mueller-Schunk S, Morhard D, et al. Intraprocedural thrombus formation during coil placement in ruptured intracranial aneurysms: treatment with systemic application of the glycoprotein IIb/IIIa antagonist tirofiban. AJNR Am J Neuroradiol 2006;27:1326-31

12. Fiorella D, Albuquerque FC, Han P, et al. Strategies for the management of intraprocedural thromboembolic complications with abciximab (ReoPro). Neurosurgery 2004;54:1089-97, discussion 1097-98

13. Gralla J, Rennie AT, Corkill RA, et al. Abciximab for thrombolysis during intracranial aneurysm coiling. Neuroradiology 2008;50: 1041-47

14. Kang HS, Kwon BJ, Roh HG, et al. Intra-arterial tirofiban infusion for thromboembolism during endovascular treatment of intracranial aneurysms. Neurosurgery 2008;63:230-37, discussion 237-38

15. Linfante I, Etezadi V, Andreone V, et al. Intra-arterial abciximab for the treatment of thrombus formation during coil embolization of intracranial aneurysms. J Neurointerv Surg 2010;2:135-38

16. Mounayer C, Piotin M, Baldi S, et al. Intraarterial administration of abciximab for thromboembolic events occurring during aneurysm coil placement. AJNR Am J Neuroradiol 2003;24:2039-43

17. Park JH, Kim JE, Sheen SH, et al. Intraarterial abciximab for treatment of thromboembolism during coil embolization of intracranial aneurysms: outcome and fatal hemorrhagic complications. J Neurosurg 2008;108:450-57

18. Song JK, Niimi Y, Fernandez PM, et al. Thrombus formation during intracranial aneurysm coil placement: treatment with intra-arterial abciximab. AJNR Am J Neuroradiol 2004;25:1147-53

19. Velat GJ, Burry MV, Eskioglu E, et al. The use of abciximab in the treatment of acute cerebral thromboembolic events during neuroendovascular procedures. Surg Neurol 2006;65:352-58, discussion $358-59$

20. Gurm HS, Tamhane U, Meier P, et al. A comparison of abciximab and small-molecule glycoprotein IIb/IIIa inhibitors in patients undergoing primary percutaneous coronary intervention: a meta- analysis of contemporary randomized controlled trials. Circ Cardiovasc Interv 2009;2:230-36

21. Zeymer U, Margenet A, Haude M, et al. Randomized comparison of eptifibatide versus abciximab in primary percutaneous coronary intervention in patients with acute ST-segment elevation myocardial infarction: results of the EVA-AMI Trial. $\mathrm{J} \mathrm{Am} \mathrm{Coll} \mathrm{Cardiol}$ 2010;56:463-69

22. Friedland S, Eisenberg MJ, Shimony A. Meta-analysis of randomized controlled trials of intracoronary versus intravenous administration of glycoprotein IIb/IIIa inhibitors during percutaneous coronary intervention for acute coronary syndrome. Am J Cardiol 2011;108:1244-51

23. Fu G, Jia L, Zhao X, et al. A comparison of intracoronary with intravenous glycoprotein IIb/IIIa inhibitors during percutaneous coronary intervention in patients with acute coronary syndrome: a meta-analysis of randomized controlled trials. J Interv Cardiol 2012;25:223-34

24. Thiele H, Wohrle J, Hambrecht R, et al. Intracoronary versus intravenous bolus abciximab during primary percutaneous coronary intervention in patients with acute ST-elevation myocardial infarction: a randomised trial. Lancet 2012;379:923-31

25. Balshem H, Helfand M, Schünemann HJ, et al. GRADE guidelines. 3. Rating the quality of evidence. J Clin Epidemiol 2011;64:401-06

26. Guyatt GH, Oxman AD, Kunz R, et al. GRADE guidelines. 6. Rating the quality of evidence-imprecision. J Clin Epidemiol 2011;64: 1283-93

27. Murad MH, Swiglo BA, Sidawy AN, et al. Methodology for clinical practice guidelines for the management of arteriovenous access. $J$ Vasc Surg 2008;48:26S-30S

28. Cognard C, Weill A, Castaings L, et al. Intracranial berry aneurysms: angiographic and clinical results after endovascular treatment. $R a$ diology 1998;206:499-510

29. Cronqvist M, Pierot L, Boulin A, et al. Local intraarterial fibrinolysis of thromboemboli occurring during endovascular treatment of intracerebral aneurysm: a comparison of anatomic results and clinical outcome. AJNR Am J Neuroradiol 1998;19:157-65

30. Cho YD, Lee JY, Seo JH, et al. Intra-arterial tirofiban infusion for thromboembolic complication during coil embolization of ruptured intracranial aneurysms. Eur J Radiol 2012;81:2833-38

31. Hähnel S, Schellinger PD, Gutschalk A, et al. Local intra-arterial fibrinolysis of thromboemboli occurring during neuroendovascular procedures with recombinant tissue plasminogen activator. Stroke 2003;34:1723-28

32. Jeon JS, Sheen SH, Hwang G, et al. Intraarterial tirofiban thrombolysis for thromboembolisms during coil embolization for ruptured intracranial aneurysms. J Cerebrovasc Endovasc Neurosurg 2012;14: $5-10$

33. Koebbe CJ, Horowitz MB, Levy EI, et al. Intraarterial thrombolysis for thromboemboli associated with endovascular aneurysm coiling: report of five cases. Interv Neuroradiol 2002;8:151-58

34. Sedat J, Chau Y, Mondot L, et al. Is eptifibatide a safe and effective rescue therapy in thromboembolic events complicating cerebral aneurysm coil embolization? Single-center experience in $\mathbf{4 2}$ cases and review of the literature. Neuroradiology 2014;56:145-53

35. Walsh RD, Barrett KM, Aguilar MI, et al. Intracranial hemorrhage following neuroendovascular procedures with abciximab is associated with high mortality: a multicenter series. Neurocrit Care 2011; 15:85-95 